UNIVERSIDADE DE SÃO PAULO

FACULDADE DE DIREITO

DANIEL BATISTA PEREIRA SERRA LIMA

\title{
DEFINIÇÃO, CONCRETIZAÇÃO E EVOLUÇÃO DAS NORMAS DE COMPETÊNCIA TRIBUTÁRIA.
}

São Paulo

2016 


\title{
DEFINIÇÃO, CONCRETIZAÇÃO E EVOLUÇÃO DAS NORMAS DE COMPETÊNCIA TRIBUTÁRIA.
}

\begin{abstract}
Dissertação apresentada à Banca Examinadora do Programa de PósGraduação em Direito, da Faculdade de Direito da Universidade de São Paulo, como exigência parcial para obtenção do título de Mestre em Direito, na área de concentração: Direito Econômico, Financeiro e Tributário, sob orientação do Prof. Associado Dr. Estevão Horvath.
\end{abstract}

São Paulo 
Autorizo a reprodução e divulgação parcial deste trabalho, por qualquer meio convencional ou eletrônico, para fins de estudo e pesquisa, desde que citada a fonte.

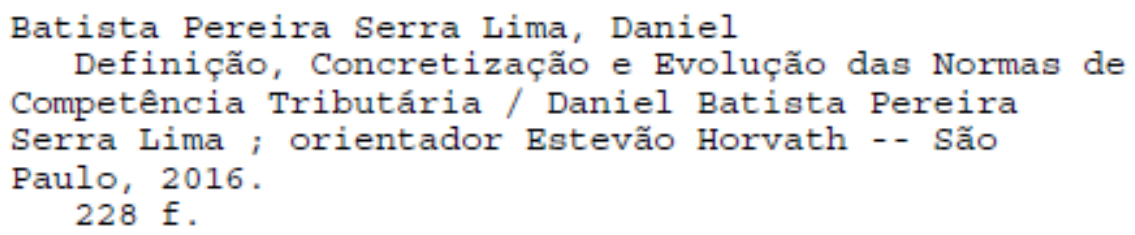

1. Competência Tributária. 2. Mutação

Constitucional. 3. Interpretação da Norma Tributária. 4. Intertextualidade. 5. Interdisciplinaridade. I. Horvath, Estevão, orient. II. Título. 
Nome: Daniel Batista Pereira Serra Lima

Título: Definição, Concretização e Evolução das Normas de Competência Tributária.

Dissertação apresentada à Banca Examinadora do Programa de Pós-Graduação em Direito, da Faculdade de Direito da Universidade de São Paulo, como exigência parcial para obtenção do título de Mestre em Direito, na área de concentração: Direito Econômico, Financeiro e Tributário

Banca realizada em:

Resultado:

Banca Examinadora

Prof. Dr.

Julgamento:

Prof. Dr.

Julgamento:

Prof. Dr.

Julgamento:
Instituição:

Assinatura:

Instituição:

Assinatura:

Instituição:

Assinatura: 


\section{AGRADECIMENTOS}

Agradeço ao meu orientador, Prof. Dr. Estevão Horvath, não apenas pela oportunidade de estudar na prestigiada Faculdade de Direito da Universidade de São Paulo, mas também pela liberdade e apoio concedidos para trilhar os caminhos que eu considerei mais apropriados ao longo do trabalho. Agradeço também ao Prof. Paulo Ayres Barreto pela atenção dispensada nas aulas e pela paciência em sanar as inúmeras dúvidas que surgiram neste percurso.

Aos Professores Eduardo Maneira e Donovan Lessa que me incentivaram a ingressar na vida acadêmica, e compreenderam todas as ausências no trabalho para dedicação ao curso de mestrado. Agradeço ainda à convivência diária de todo os colegas integrantes do Maneira Advogados, que tiveram coragem para se lançar neste bemsucedido desafio.

Aos amigos feitos na pós-graduação da Faculdade de Direito da USP, que tornaram mais prazerosa a cansativa rotina de aulas e seminários.

Por fim, aos meus amigos e familiares, especialmente minha mãe, meus irmãos, e à Vanessa, por todo o apoio. 
"O ideal de erradicar erros deve ser extirpado da ciência como erva daninha."

José Souto Maior Borges 


\section{RESUMO}

LIMA, Daniel Batista Pereira Serra. Definição, Concretização e Evolução das Normas de Competência Tributária. 2016. 228 f. Mestrado - Faculdade de Direito, Universidade de São Paulo, São Paulo, 2016.

O presente estudo dedica-se à interpretação das regras que formam o sistema de repartição de competências tributárias da Constituição Federal de 1988. Para melhor compreensão do tema, a primeira e segunda partes voltam-se à apresentação do direito como um sistema que se opera através da linguagem, e os principais aspectos da teoria da interpretação. Na terceira parte é realizada uma análise histórica do sistema de discriminação de rendas tributárias, uma teorização sobre a função da regra de repartição de competências e sua influência sobre o fechamento das possibilidades interpretativas. Na quarta parte, discorrese sobre as teorias da interpretação da lei tributária. Na quinta parte pretende-se demonstrar que as mutações constitucionais podem afetar as regras de repartição de competência tributária, atualizando-as às novas realidades, bem como os limites a este fenômeno. Na sexta e última parte as propostas anteriores são confrontadas com a jurisprudência do Supremo Tribunal Federal sobre o tema.

Palavras-chave: Competência Tributária; Interpretação da Norma Tributária; Mutação Constitucional; Intertextualidade; Interdisciplinaridade. 


\begin{abstract}
LIMA, Daniel Batista Pereira Serra. Definition, Interpretation and Evolution of Tax Competence Rules. 2016. 228 p. Master Degree - Faculty of Law, University of São Paulo, São Paulo, 2016.

This paper focusses on the interpretation of the rules that form the 1988 Brazilian Constitutional Tax Competence system. In order to enable a better understanding of the subject, the first and second parts analyzes law as a social system that works through language itself, and the main aspects of the theory of legal interpretation. In the third part a historical analysis of the Brazilian Constitutional Tax Framework is carried out, including the theorization about the function of the tax competence rule, and its influence on the interpretation. The fourth part discusses theories regarding the interpretation of tax laws. The fifth part is intended to demonstrate that the constitutional changes might affect the rules of tax jurisdiction, updating them to new realities, as well as its limits. In the sixth and last part, the previous proposals are contrasted with the jurisprudence of the Federal Supreme Court.
\end{abstract}

Keywords: Tax Competence; Interpretation of Tax Law; Constitutional Mutation; Intertextuality; Interdisciplinary. 


\section{SUMÁRIO}

INTRODUÇÃ

1. LINGUAGEM E NORMAS JURÍDICAS .............................................................07

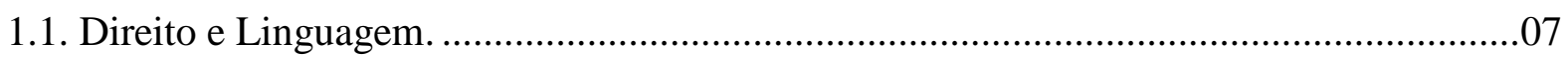

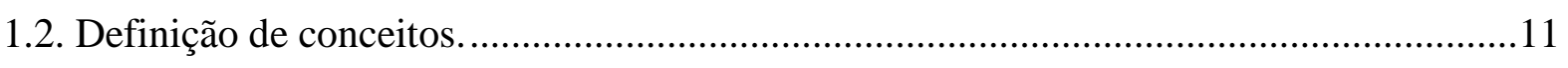

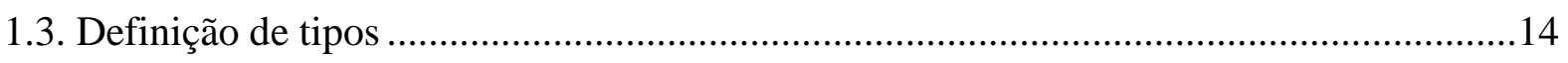

1.4. Críticas à distinção entre tipos e conceitos como modo de aplicação do direito..............16

1.5. Tipos e conceitos no Direito Tributário ..................................................................... 18

1.5.1. A utilização de conceitos classificatórios como decorrência da legalidade ..................18

1.5.2. A tipicidade aberta como decorrência de complexidade social...................................21

1.5.3. A linha adotada: a especificação conceitual como decorrência da função limitadora

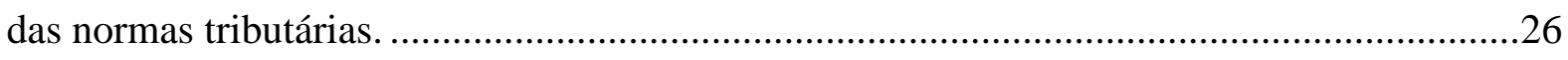

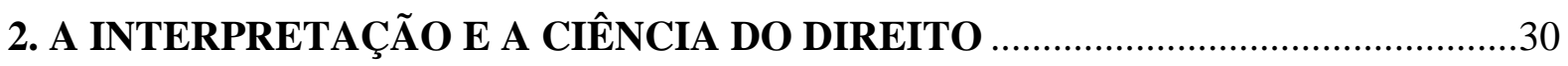

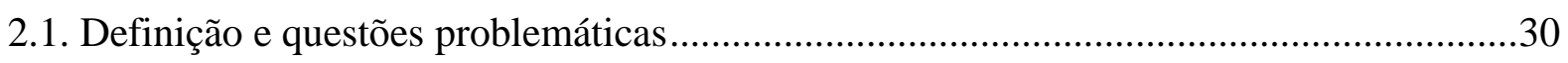

2.2. Interpretação como ato de conhecimento, de decisão e de criação do direito ...................31

2.3. A teoria da interpretação adotada: o ceticismo moderado...............................................33

2.4. Da interpretação à aplicação do direito: a possibilidade de interpretar os textos

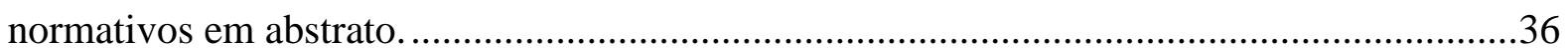

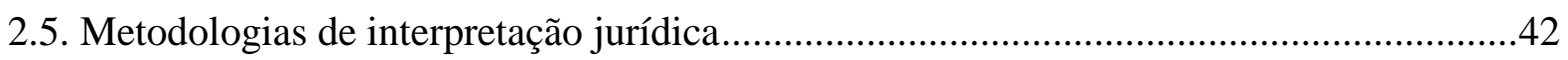

2.5.1. O percurso gerador de sentido de Barros Carvalho ..................................................42

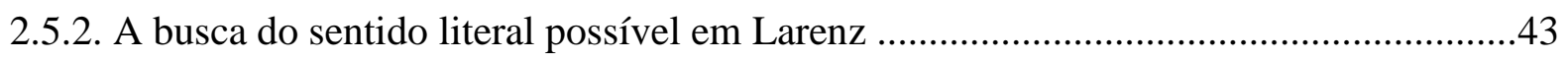

2.6. Porque conferir peso aos argumentos que justificam a interpretação jurídica ao invés

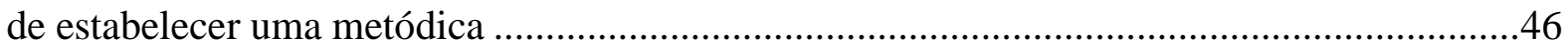

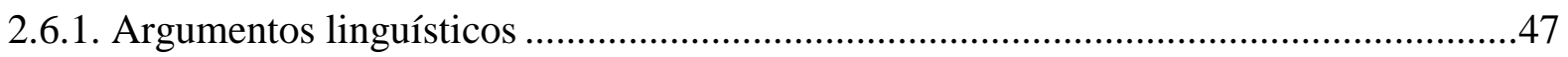

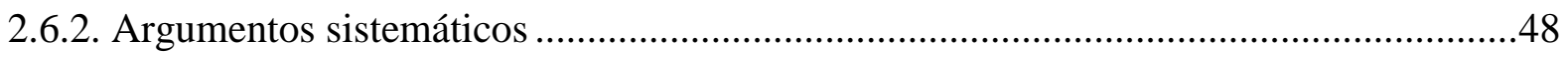

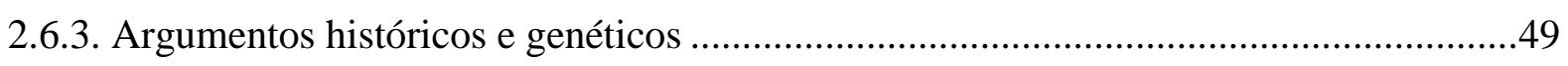

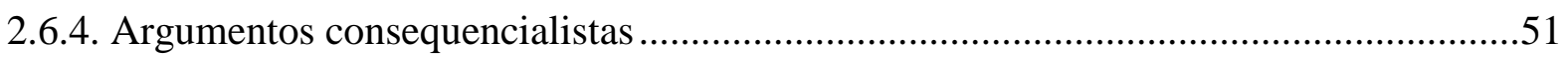

2.6.5. Prevalência dos argumentos linguísticos e sistemáticos sobre os demais .....................52

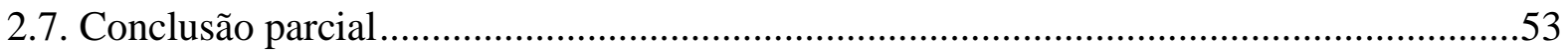

3. A REPARTIÇÃO CONSTITUCIONAL DE COMPETÊNCIAS TRIBUTÁRIAS....55

3.1. Definição e características da competência tributária.......................................................55 
3.2. A opção pela repartição constitucional de competências tributárias através da nominação de impostos e contribuições. .57

3.3. Repartição de competências: uma decorrência do federalismo? .....................................59

3.4. Histórico da repartição de competências tributárias. ....................................................61

3.5. A natureza das normas atributivas de competência tributária. ......................................66

3.5.1. Diferenças conceituais entre princípios e regras..........................................................66

3.5.2. A repartição de competência tributária através de regras ............................................68

3.5.3. A subeficácia dos princípios constitucionais sobre as regras de competência. ............69

3.6. Justificativa e função das regras de competência tributária.............................................74

3.6.1. Justificativa de regras e justificativa geradora de regras ............................................74

3.6.2. Justificativa geradora das regras de competência ..................................................... 76

3.6.3. A função protetiva das regras de competência ............................................................ 78

3.6.4. A regra de permissibilidade expressa implícita no art. 154, II, da CF/88 ....................80

3.7. Da força vinculante das regras atributivas de competência ...........................................82

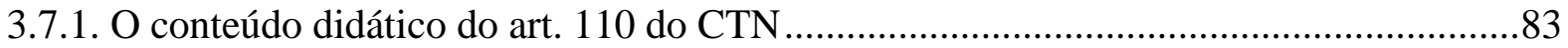

3.8. A existência de conceitos classificatórios nas normas atributivas de competência

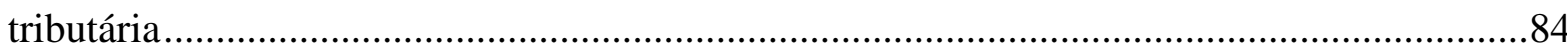

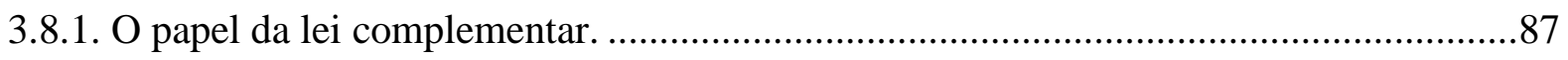

3.8.2. A repartição de competências por conceitos classificatórios e o espectro de liberdade

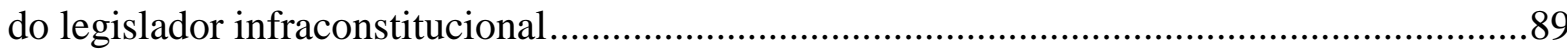

\section{A CONSTRUÇÃO DE SENTIDO DAS NORMAS CONSTITUCIONAIS DE} COMPETÊNCIA TRIBUTÁRIA

4.1. A intertextualidade e interdisciplinaridade: definições. .92

4.2. Interdisciplinaridade: o Direito Tributário e outras Ciências ............................................94

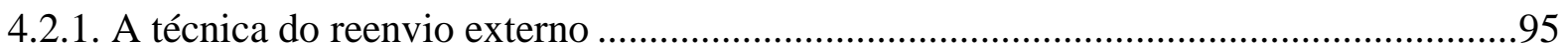

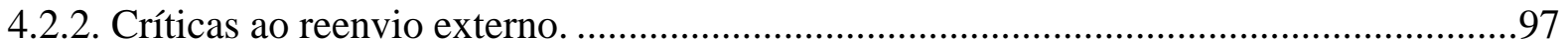

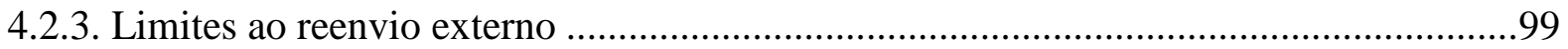

4.2.4. Impossibilidade de reenvio externo ao nível constitucional: os conceitos têm

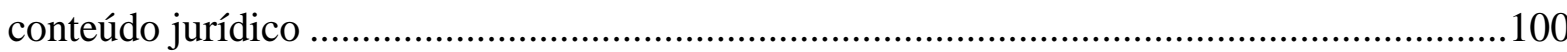

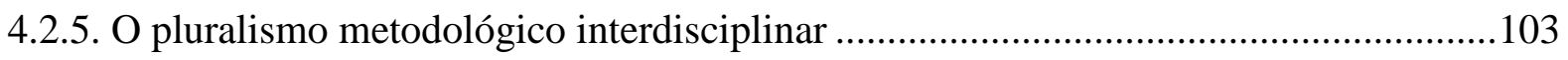

4.3. Intertextualidade: o Direito Tributário e outros ramos do Direito...................................105

4.3.1. A possibilidade de criação de conceitos tributários autônomos: rejeição à concepção do direito tributário como um direito de superposição (ou sobreposição). ............................105

4.3.2. Hipóteses de interação entre direito tributários e outros ramos do direito. ..................108 
4.3.3. O crivo da razoabilidade como barreira à autonomia conceitual.

4.3.4. A incorporação dos conceitos jurídicos pelo direito tributário pode ser presumida....111

4.3.5. O conteúdo do art. 109 do CTN.

4.3.5.1. O art. 109 do CTN não autoriza a mutação conceitual...........................................113

4.4. Sobre a interpretação econômica das leis tributárias....................................................115

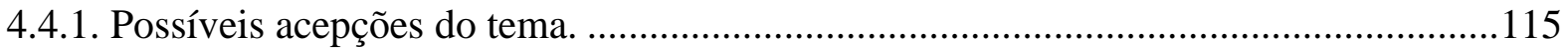

4.4.2. A tentativa de introdução da interpretação teleológica no CTN..................................116

4.4.3. Origem da interpretação econômica da lei tributária na Alemanha.............................118

4.4.4. A interpretação econômica no pluralismo metodológico ...........................................122

4.4.4.1. A restrita aplicabilidade de critérios econômicos ..................................................123

4.5. Hipóteses de construção de conceitos constitucionais .................................................125

4.5.1. Construção de conceitos autônomos ....................................................................... 125

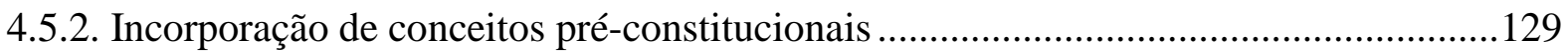

4.5.2.1. Inexistência de reenvio interno: a irrelevância da posterior alteração do conceito na legislação de origem

4.5.3. A deformação do conceito jurídico pré-constitucional pelo contexto constitucional.. 132

4.5.4. A influência dos princípios na interpretação da regra de competência 135

4.5.4.1. A função dos princípios na construção do conceito dentro dos sentidos possíveis ..136

4.5.4.2. A relevância do princípio da capacidade contributiva na interpretação ....................138

5. A EVOLUÇÃO DA COMPETÊNCIA TRIBUTÁRIA..................................................141

5.1. Formas de modificar a Constituição …………................................................................ 142

5.2. Breves comentários acerca da mutação constitucional .................................................144

5.2.1. Distinção entre mutação constitucional e evolução interpretativa...............................144

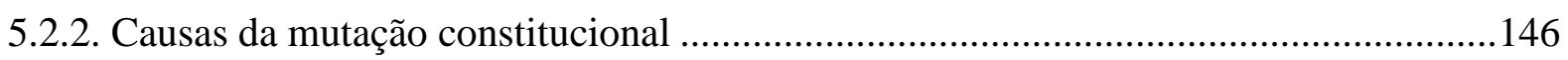

5.2.2.1. A mutação como reconhecimento de um fato consumado. ......................................147

5.2.2.2. A mutação como decorrência da influência do caso concreto na interpretação ........149

5.2.2.3. A mutação é possível porque o Direito se opera através da linguagem ...................150

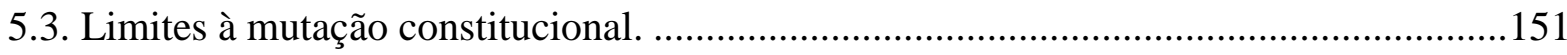

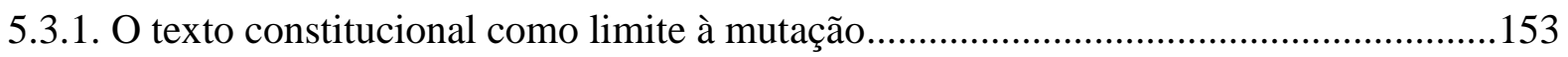

5.4. A modificação tácita da competência tributária .........................................................156

5.4.1. A (relativa) relevância da posterior alteração do conceito de origem .........................159

\section{A INTERPRETAÇÃO DAS REGRAS DE COMPETÊNCIA NA} JURISPRUDÊNCIA DO SUPREMO TRIBUNAL FEDERAL ...................................161

6.1. Contribuição social sobre a folha de salários e demais rendimentos do trabalho............162 
6.2. Imposto sobre serviços de qualquer natureza

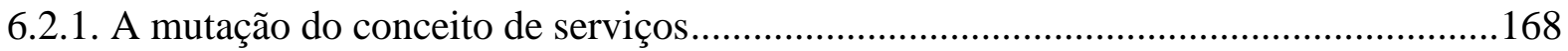

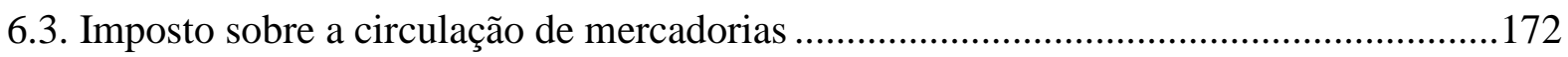

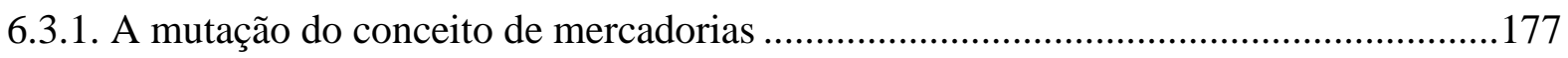

6.4. Imposto sobre a propriedade de veículos automotores .................................................182

6.5. Contribuição social sobre a receita ou faturamento .....................................................184

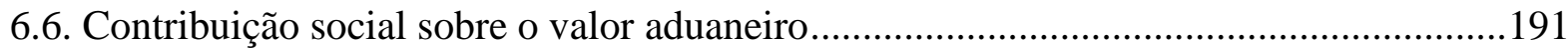

6.7. Imposto sobre a renda e proventos de qualquer natureza ..........................................195

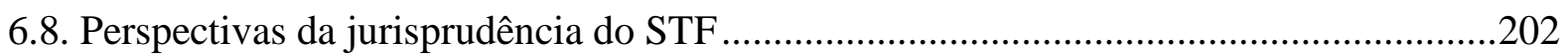

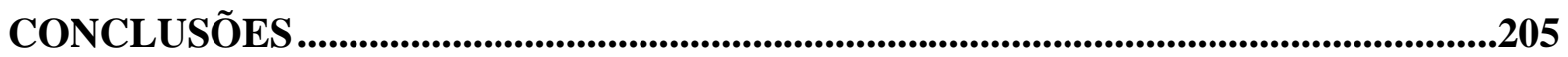

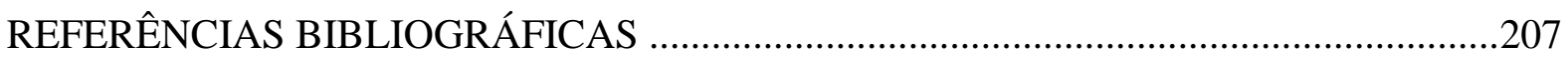




\section{INTRODUÇÃO.}

Como recorrentemente apregoado pela doutrina ${ }^{1}$, a Constituição Federal de 1988 foi excessivamente analítica em matéria tributária, inundando seu texto com princípios e vedações atinentes à tributação, o que não guarda paralelo em constituições estrangeiras $^{2}$. Além disso, o Poder Constituinte se preocupou em apontar quais tributos poderiam ser instituídos pelos Municípios, Estados, Distrito Federal e pela União ${ }^{\mathbf{3}}$, e também sobre quais materialidades, vale dizer, sobre quais fatos denotativos de capacidade econômica, cada exação poderia recair.

Isso quer dizer que, em nosso ordenamento jurídico, o legislador infraconstitucional não tem liberdade para instituir tributos sobre os fatos que melhor lhe aprouver, devendo respeitar a competência que lhe foi outorgada pela Constituição Federal. A jurisprudência do Supremo Tribunal Federal e a doutrina ${ }^{4}$ não parecem discordar sobre este ponto.

Entretanto, cabe uma reflexão sobre a opção do constituinte de nominar os tributos de competência privativa (impostos e contribuições sociais). Para definir os tributos que podem ser instituídos privativamente pelos entes da federação, a Carta Magna se utilizou de símbolos linguísticos, como "veículos automotores", "serviços", renda", "lucro", "folha de salários", "faturamento", "receita" e "mercadorias" dentre outros, sem se preocupar em demarcar seus atributos explicitamente.

Dada a imprecisão que é inerente à linguagem, a cada uma dessas palavras podem ser atribuídos vários significados dependendo do contexto em que são utilizadas, e as mesmas podem ter um grau de indeterminação e densidade semântica menor ou maior. E uma interpretação mais extensiva ou restritiva do alcance do enunciado constitucional pode implicar o reconhecimento de uma competência impositiva diversa (maior ou menor) do que a Constituição Federal realmente pretendia conferir ao Ente Federado.

\footnotetext{
1 Entre outros: DERZI, Misabel Abreu Machado. Modificações da Jurisprudência no Direito Tributário: Proteção da Confiança, boa-fé objetiva e irretroatividade como limitações constitucionais do poder judicial de tributar. São Paulo: Noeses, p. 01. CARVALHO, Paulo de Barros. Direito Tributário, Linguagem e Método, $3^{\mathrm{a}}$ ed. São Paulo: Noeses, 2010, p. 236.

${ }^{2}$ HORVATH, Estevão. "Conflitos de Competência (IPI, ICMS, ISS, etc.)" In DERZI, Misabel Abreu Machado (org.). Competência Tributária. Belo Horizonte: Del Rey, 2011, p. 229. COÊLHO, Sacha Calmon Navarro. Curso de Direito Tributário Brasileiro, 9a ed. Rio de Janeiro: Forense, 2007, p. 47. ${ }^{3}$ Apenas esta última tem competência residual para instituir impostos nos termos do art. 154 da CF/88

4 ÀVILA, Humberto. Sistema Constitucional Tributário, 4ª ed. São Paulo: Saraiva, 2010, p. 164-165.
} 
Assim, o grande problema é justamente como delimitar a extensão desses enunciados utilizados pela $\mathrm{CF} / 88$ para definir a competência tributária da União, Estados, Distrito Federal e Municípios.

Trata-se, portanto, de tema de grande relevância, uma vez que a delimitação da competência impositiva é o ponto de partida para toda e qualquer análise de incidência da norma tributária. Talvez por esse motivo, a extensão da competência tributária prevista na Constituição Federal sempre foi causa de divergências entre Fisco e contribuintes, doutrina e jurisprudência. Pelo mesmo motivo, se avolumam os estudos que tratam exclusivamente da matéria, valendo citar os trabalhos de VELLOSO ${ }^{5}$, MACHADO $^{6}$ e PIZZOLIO. ${ }^{7}$

Por outro lado, o dinamismo da sociedade (com o surgimento de novas fontes de riquezas) e da própria linguagem (que evolui para alcançar novas realidades) impõe uma constante revisitação do tema, até mesmo para entender se a competência tributária pode (ou deve) evoluir pela via interpretativa ou se é necessária a alteração do enunciado positivado via emenda constitucional.

Se é certo, como lembra $\mathrm{BARROSO}^{8}$, que "as constituições têm vocação de permanência (...) nada obstante isso, as constituições não são eternas nem podem ter a pretensão de ser imutáveis", seria possível compatibilizar o dinamismo da Constituição com segurança jurídica? Lado outro, a tentativa de entronização da segurança jurídica pela cristalização da competência tributária seria compatível com os demais princípios e valores constitucionais?

A solução dessa controvérsia passa pela constante tensão entre os valores basilares do sistema jurídico 9 (justiça e segurança), já que um não sobrevive sem o outro. ${ }^{10}$ Com efeito, um sistema jurídico que busque ao máximo a justiça material com

\footnotetext{
${ }^{5}$ MACHADO, Raquel Cavalcanti Ramos. Competência Tributária: entre a rigidez do sistema e a atualização interpretativa. São Paulo: Malheiros, 2014.

${ }^{6}$ VELLOSO, Andrei Pitten. Conceitos e Competências Tributárias. São Paulo: Dialética, 2005.

7 PIZZOLIO, Reinaldo. Competência Tributária e Conceitos Constitucionais. São Paulo: Quartier Latin, 2006.

8 BARroso, Luís Roberto. Curso de Direito Constitucional Contemporâneo, 2a ed. São Paulo: Saraiva, 2010, p. 123.

9 “A segurança jurídica, nessa acepção, é um valor que, ao lado da justiça e da paz social, inspira qualquer ordenamento jurídico no seu conjunto.” (ÁVILA, Humberto. Segurança Jurídica: entre permanência, mudança e realização no Direito Tributário. São Paulo: Malheiros, 2011, p. 126)

${ }^{10}$ Sobre a ambivalência (ou polaridade) dos valores constitucionais, Ricardo LOBO TORRES afirma: "Da mesma forma que há colisões entre os diversos valores, que devem ser superadas por obra do jurista, também cada valor jurídico traz em si o germe de sua própria negação. Nenhum valor jurídico reina de modo absoluto, pois caminha sempre para a sua própria contrariedade." (TORRES, Ricardo Lobo. Tratado de Direito Constitucional, Financeiro e Tributário: valores e princípios constitucionais tributários. Rio de Janeiro: Renovar, vol. II, 2014, p. 45-46)
} 
a flexibilização das normas positivadas seria injusto, pois as pessoas não poderiam ordenar sua conduta de acordo com uma regra preexistente. Em outras palavras, faltaria previsibilidade, criando um estado de insegurança e, consequentemente, injustiça individual. $^{11}$

Por outro lado, em um sistema jurídico no qual os conceitos legais sejam unívocos e interpretados estaticamente existirá segurança interpretativa, mas o mesmo pode se verificar injusto uma vez que as normas abstratas não serão capazes de prever a multiplicidade de casos que irão ocorrer sob a sua égide, tratando da mesma maneira situações díspares. Nesse caso, faltará coerência o que gera injustiça. Da injustiça decorre o descrédito nas regras, levando à insegurança. ${ }^{12}$

Dada a peculiaridade da Constituição Brasileira que optou por repartir diretamente as faixas de competência tributária, a primeira questão que se coloca, é, evidentemente, qual a função das normas atributivas de competência tributária, o que poderá influenciar como as mesmas devem ser interpretadas.

De um lado, em se concluindo que as normas de competência têm por objetivo conferir segurança jurídica aos contribuintes, tanto maior será a rigidez que as mesmas devem ostentar. Lado outro, caso se conclua que tais normas não exercem essa função, mas prestam-se tão somente a evitar conflitos entre os entes federados, seria possível reconhecer maior flexibilidade aos enunciados, desde que não ocorresse a sobreposição.

Seguindo essa linha, a segunda questão que se pretende responder é quanto ao grau de flexibilidade que o legislador infraconstitucional tem para manipular as hipóteses de incidência dos tributos que serão instituídos dentro da faixa de competência. Para tanto, imprescindível definir se tais enunciados constitucionais representam tipos (aqui tomando-se a palavra em sentido estrito, sob as lições de DERZI $^{13}$ ), ou seja, com contornos abertos e flexíveis, ou se, ao revés, configuram conceitos classificatórios, com características fixas e irrenunciáveis.

Em se concluindo que os enunciados constitucionais se utilizam de tipos, portanto, estruturas abertas, devem ser definidas as características que compõem o tipo ainda que a ausência de uma delas não desnature a incidência da norma. Se, ao revés, a conclusão for pela existência de conceitos classificatórios a necessidade de construir esses conceitos e delimitá-los é evidentemente maior, uma vez que a ausência de

\footnotetext{
${ }^{11}$ Ibid, p. 156 e 160.

${ }^{12}$ Ibid, p. 170-171.

13 DERZI, Misabel de Abreu Machado. Direito Tributário, Direito Penal e Tipo, $2^{\text {a }}$ ed. São Paulo: Revista dos Tribunais, 2007.
} 
qualquer dos elementos denotadores dos conceitos acarretaria a inadequação material da lei à faixa de competência prevista na Constituição.

A terceira questão diz respeito à construção de sentido desses enunciados. Como visto, ora o Texto Constitucional se utiliza de signos oriundos de outras áreas do Direito (notadamente o Direito Privado, como a propriedade e a doação), ora se utilizou de conceitos originários de outras ciências como a economia (renda), a contabilidade (receita), ainda de expressões de fundo sociológico, como no caso das grandes fortunas.

Seria possível interpretar cada signo tal como estabelecido pela ciência de origem, isto é, interpretar juridicamente a propriedade, economicamente a renda, contabilmente a receita e sociologicamente a grande fortuna? Ou, considerando que o tributo busca gravar demonstrações de riqueza, faria mais sentido interpretar todos estes signos economicamente, privilegiando a finalidade arrecadatória? Uma terceira possibilidade é a de privilegiar o sentido técnico-jurídico das palavras. Em se adotando essa corrente, tal sentido técnico-jurídico, deve ser construído especificamente para a norma de competência? Ou, lado outro, deve-se adotar os sentidos preexistentes no ordenamento jurídico?

Ainda neste ponto é preciso analisar a influência dos princípios constitucionais tributários, como a capacidade contributiva e a solidariedade, sobre a interpretação dos signos utilizados para repartir a competência tributária. Segundo GRECO $^{14}$, o princípio da capacidade contributiva se irradiaria por todo o Sistema Constitucional Tributário, por ser a justiça fiscal o seu fundamento último. Nessa toada, a interpretação dos enunciados definidores da competência tributária também deveria levar tais princípios em consideração? Se sim, em que medida?

Assim, o presente trabalho também terá por escopo analisar a eficácia do Princípio da Capacidade Contributiva como vetor interpretativo dos enunciados constitucionais, e a possibilidade de realizar uma interpretação extensiva ou ampliativa da faixa de competência com base em princípios.

Por fim, definidas as características que formam o enunciado constitucional impende verificar a possibilidade de evolução ou mutação desses. Poderia o Direito,

14 "No texto da $\mathrm{CF} / 88$, a capacidade contributiva assume importante e caráter muito mais relevante do que anteriormente se lhe reconhecida. A capacidade contributiva é verdadeiro princípio informador do sistema tributário como um todo. É diretriz positiva da sua conformação. Nesse sentido, por dizer respeito à composição estrutural do sistema, sua aplicação dá-se antes mesmo da aplicação do princípio da igualdade tributária que, alias, se apresenta como 'limitação' (previsão de caráter negativo) ao poder de tributar (CF/88, artigo 150, II).” (GRECO, Marco Aurélio. Planejamento Tributário, $2^{\mathrm{a}}$ ed. São Paulo: Dialética, 2008, p. 318) No mesmo sentido: RIBEIRO, Ricardo Lodi. Justiça, Interpretação e Elisão Tributária. Rio de Janeiro: Lumen Juris, 2003, p. 88-89. 
como ciência estabilizadora dos conflitos sociais, ignorar a evolução das relações econômicas pelo mundo, mormente quando essa evolução passa pela alteração de conceitos e institutos amplamente utilizados pelo ordenamento jurídico?

Em princípio, é difícil conceber que um conceito utilizado pelo constituinte em 1988 (como o conceito de serviços, ou de comunicação) deva permanecer cristalizado mesmo diante da constante evolução tecnológica, econômica e social contemporânea ${ }^{15}$, pois o Direito não pode ficar insensível às mudanças sociais e econômicas, mormente quando suas normas têm o dever de agir sobre fatos da realidade. ${ }^{16}$

Nesse ponto, há que se perquirir sobre a possibilidade de evolução desses conceitos definidores de competência tributária.

Ora, é sabido que toda Constituição deve prever formas para sua atualização, sob pena de se tornar ultrapassada. É, inclusive, a função das emendas constitucionais. Entretanto, nos casos em que a Lei Maior se utilizou de signos oriundos de outras ciências, ou outros ramos do Direito, que influência terá no Direito Tributário a modificação desses conceitos na ciência de origem ou no seu uso corrente? É razoável defender uma interpretação dinâmica da competência tributária para que a mesma possa novas formas de circulação de riqueza congêneres às já previstas no Texto Constitucional? Se sim, quais seriam os limites (se é que existem) para essa mudança?

Portanto, o presente trabalho também deve analisar a possibilidade de mutação ou reinterpretação (construtiva ou evolutiva) dos enunciados constitucionais que outorgam competência tributária, o que é de grande valia dada a recente estabilização institucional do Brasil e a relativa longevidade da atual Constituição Federal.

Em síntese, os questionamentos que se pretende ver respondidos são:

1) É possível falar em "tipicidade cerrada" ao nível constitucional? Os enunciados que definem competência tributária seriam tipos (e, portanto, abertos) ou conceitos classificatórios? Essa discussão ainda é relevante?

2) Qual a função da técnica de repartição de competências utilizada pela $\mathrm{CF} / 88$ ? Apenas evitar conflito de competências ou garantir alguma forma de segurança aos contribuintes? Essa função exerce alguma influência sobre

\footnotetext{
15 RIBEIRO, Ricardo Lodi. A Segurança Jurídica do Contribuinte: Legalidade, não surpresa e proteção à confiança legítima. Rio de Janeiro: Lumen Juris, 2008, p. 34.

16 GRAU, Eros Roberto. "A Interpretação do Direito e a Interpretação do Direito Tributário". in CARVALHO, Maria Augusta Machado de (coord.). Estudos de Direito Tributário em Homenagem à Memória de Gilberto de Ulhôa Canto. Rio de Janeiro: Forense, 1998, p. 124.
} 
ordenamento jurídico? Os signos utilizados na repartição de competência tributária representam limites ao legislador?

3) Há uma metodologia mais adequada para a interpretação e construção dos enunciados que outorgam competência tributária? Há uma hierarquia entre os elementos de interpretação? Devemos interpretar diferentemente os enunciados que utilizam conceitos oriundos de direito privado e os que utilizam conceitos oriundos de outras ciências?

4) Os princípios constitucionais da capacidade contributiva e da solidariedade influenciam a interpretação dos enunciados que outorgam competência tributária?

5) Como se dá a evolução dos enunciados que outorgam competências tributárias no tempo? Conceitos já estabilizados podem sofrer mutação tácita em razão da dinâmica social? E no caso de alteração do conceito na ciência ou no ramo jurídico de origem (Direito Privado, Economia ou Contabilidade)?

A investigação do objeto proposto se dará por intermédio de uma análise dogmática, com foco na dimensão normativa. A dogmática jurídica divide-se em três planos distintos: analítico, empírico e normativo. ${ }^{17}$ Em apertada, no plano analítico, a dogmática jurídica se refere à "dissecação sistemático-conceitual" do direito positivo, desde a análise de conceitos elementares, passando por construções jurídicas até o exame da estrutura do sistema jurídico. No plano empírico pode ser visto em relação à compreensão do direito positivo válido (incluindo a jurisprudência), ou quanto à aplicação de premissas empíricas na argumentação jurídica (como os argumentos consequencialistas). Já a dimensão normativa busca elucidar e analisar criticamente a práxis jurídica, sobretudo a jurisprudencial. Nessa linha, parte do direito vigente, e busca determinar a solução correta para um caso concreto, através da fundamentação racional da decisão.

\footnotetext{
17 ALEXY, Robert. Teoria dos direitos fundamentais, $2^{\mathrm{a}}$ ed. SILVA, Virgílio Afonso da (trad.). São Paulo: Malheiros, 2008, p. 32-36.
} 


\section{CONCLUSÕES}

1. O direito é um sistema comunicacional que, não apenas se opera, mas principalmente, é produzido pela linguagem, o que atrai uma série de consequências, notadamente em razão da flexibilidade que é inerente àquela.

2. Todo nome é convencionalmente atribuído a um objeto a partir de uma generalização de modo a tornar possível a comunicação ao seu destinatário. A seleção de características rígidas para estabelecer uma generalização (conceito) não impede a atualização deste mesmo conceito conforme o evoluir da linguagem e da vida social.

3. Nesse sentir, prevalece a dissecção da realidade em conceitos, que classificam os fatos da realidade através de notas distintivas, com a identificação dos casos semelhantes para que a eles sejam imputadas idênticas consequências jurídicas.

5. Os princípios que informam o direito tributário (como a legalidade) exigem a maior cognoscibilidade possível quanto aos elementos da obrigação tributária (ainda que uma determinabilidade absoluta seja impossível), o que revela a primazia da função limitadora da norma tributária, aproximando-as do pensamento por conceitos.

6. A indicação, já no Texto Constitucional, das competências tributárias pelos nomes dos impostos e contribuições sociais que podem ser instituídos através de institutos jurídicos distintos e inconfundíveis, tem por objetivo trazer maior segurança jurídica aos contribuintes, por trazer um limite material à própria competência legislativa delegada.

7. Algumas peculiaridades da $\mathrm{CF} / 88$ como o federalismo entre três ordens de governo, a rigidez do sistema de repartição de competências e a necessidade de conferir segurança jurídica aos contribuintes, evitando-se múltiplas incidências sobre os mesmos fatos jurídicos, autorizam a conclusão de uma tendência à utilização de conceitos classificatórios nas normas constitucionais de repartição de competência tributária.

8. Quanto ao seu conteúdo, as normas de competência são dotadas de densidade normativa e conteúdo eminentemente jurídico, o que é incompatível com um reenvio ao nível constitucional.

9. Não é possível estabelecer aprioristicamente uma metodologia para a sua reconstrução: esta dependerá da argumentação jurídica e da força das justificativas apresentadas. Nessa argumentação deverão ter primazia os argumentos semânticos e sistemáticos, eis que decorrem diretamente do texto positivado (logo, privilegia a 
representatividade democrática) e conferem coerência, segurança e previsibilidade ao ordenamento.

10. Os argumentos históricos e genéticos, por sua vez, passariam a ter relevância quando os argumentos linguísticos e sistemáticos não sejam suficientes para justificar adequadamente uma interpretação, restando mais de uma opção igualmente coerente. Já os argumentos consequencialistas seriam meramente retóricos, sem peso para justificar uma ou outra decisão.

11. Nesse sentido, a teoria que defende a incorporação prima facie propõe um ponto de partida e um limite para a reconstrução: os conceitos constitucionais são formados a partir das formas jurídicas preexistentes (sejam elas de direito privado, de direito tributário ou qualquer outro ramo), cabendo sua deformação conceitual para a adequação de tais institutos ao contexto constitucional, sempre dentro dos limites admitidos pela interpretação literal (cognitiva).

12. Os princípios da capacidade contributiva e da solidariedade não têm o condão de autorizar a criação de novos tributos no Brasil, pois o exercício do poder tributário foi expressamente delimitado pelas regras de competência inseridas no Texto Constitucional, deixando pouca liberdade nesse âmbito para a União e nenhuma para os Estados e Municípios.

13. Por outro lado, os princípios exercem influência na construção da norma de competência através da escolha, dentre as possibilidades semânticas contidas no sentido literal possível, daquela que melhor atenda aos princípios constitucionais.

14. A mutabilidade (tecnológica, econômica, política e social) pode criar novas realidades análogas aos conceitos anteriormente estabelecidos, que acabam sendo incorporadas no mundo dos fatos aos conceitos jurídicos, no que se denomina mutação conceitual.

15. Essa mutação conceitual pode acarretar uma mudança de interpretação nos dispositivos que limitam as regras de competência tributária, o que implica na modificação tácita da competência atribuída. Contudo, a mutação conceitual somente poderá atingir novas realidades, que não poderiam ter sido previstas pelo Constituinte de 1988. 


\section{REFERÊNCIAS BIBLIOGRÁFICAS.}

ALEXY, Robert. Teoria dos direitos fundamentais, $2^{\mathrm{a}}$ ed. SILVA, Virgílio Afonso da (trad.). São Paulo: Malheiros, 2008.

ALVES, Raquel de Andrade Vieira. O Abuso na Instituição de Contribuições pela União e o Federalismo Fiscal Brasileiro. Dissertação de Mestrado. Rio de Janeiro: UERJ, 2015.

AMARO, Luciano. Direito Tributário Brasileiro, 13ª ed. São Paulo: Saraiva, 2007.

ANDRADE, José Maria Arruda. Interpretação da Norma Tributária. São Paulo: MP Editora, 2006.

- "Interpretação e Aplicação da Lei Tributária: da Consideração Econômica da Lei Tributária à Análise Econômica do Direito" in MACHADO, Hugo de Brito (coord.) Interpretação e Aplicação da Lei Tributária. São Paulo: Dialética, 2010.

ATAliBA, Geraldo. Sistema Constitucional Tributário Brasileiro. São Paulo: Revista dos Tribunais, 1968.

ÁVILA, Humberto. "Argumentação Jurídica e a Imunidade do Livro Eletrônico" in Revista Eletrônica de Direito do Estado. Salvador: Instituto Brasileiro de Direito Público, jan/fev/mar/2010, $\mathrm{n}^{\circ}$ 21. Disponível em http://www.direitodoestado.com.br Acesso em 09.09.2016.

. "Ciência do Direito Tributário e Discussão Crítica". In: ZILVETI, Fernando Aurélio (coord.) Direito Tributário Atual, São Paulo: Dialética, 2014, no 32.

Paulo: Malheiros, 2011.

Conceito de Renda e Compensação de Prejuízos Fiscais. São

"A Doutrina e o Direito Tributário" in ÁVILA, Humberto (org.)

Fundamentos do Direito Tributário. São Paulo: Marcial Pons, 2012.

. "Eficácia do Novo Código Civil na Legislação Tributária." In. GRUPPENMARCHER, Betina Treiger (coord.) Direito Tributário e o Novo Código Civil. São Paulo: Quartier Latin, 2004.

- "Função da Ciência do Direito Tributário: do Formalismo Epistemológico ao Estruturalismo Argumentativo." In: OLIVEIRA, Ricardo Mariz et. al. (coord.) Direito Tributário Atual. São Paulo: Dialética, 2013, nº 29.

"ICMS como Imposto sobre o Consumo. Inocorrência de Prestação de Onerosa de Serviço de Comunicação no Caso de Inadimplemento do Consumidor." In Revista Dialética de Direito Tributário. São Paulo: Dialética, Março/2011, nº 186. 
. "Limites à Tributação com Base na Solidariedade Social" in GRECO. Marco Aurélio; GODOI, Marciano Seabra de. (coord.) Solidariedade Social e Tributação. São Paulo: Dialética, 2005.

"Neoconstitucionalismo: entre a ciência do direito e o direito da ciência." In Revista Eletrônica de Direito do Estado. Salvador: Instituto de Direito Público. No 17. Jan/Fev/Mar, 2009. Disponível em: http://www.direitodoestado.com.br Acesso: 04/10/2014.

Segurança Jurídica: entre permanência, mudança e realização no Direito Tributário, $2^{\mathrm{a}}$ ed. São Paulo: Malheiros, 2012.

Sistema Constitucional Tributário, $3^{\mathrm{a}}$ ed. São Paulo: Saraiva, 2008.

Teoria dos Princípios: da definição à aplicação dos princípios jurídicos. $9^{\text {a }}$ ed. São Paulo: Malheiros, 2009.

BALEEIRO, Aliomar. Limitações Constitucionais ao Poder de Tributar, $8^{\mathrm{a}}$ ed. atual. por DERZI, Misabel de Abreu Machado. Rio de Janeiro: Forense, 2010.

Direito Tributário Brasileiro, $12^{\mathrm{a}}$ ed. atual. por DERZI, Misabel de Abreu Machado. Rio de Janeiro: Forense, 2013.

BARRETO, Paulo Ayres. Contribuições: regime jurídico, destinação e controle, $2^{\text {a }}$ ed. São Paulo: Noeses, 2011.

São Paulo: USP, 2008.

Elisão Tributária: limites normativos. Tese de Livre-Docência.

Dialética, 2001.

Imposto sobre a Renda e Preços de Transferência. São Paulo:

. TAKANO, Caio Augusto. "Entre o Direito Tributário e a Nova Contabilidade: a questão da tributação dos dividendos na Lei $\mathrm{n}^{\circ} 12.973 / 2014$." In ROCHA, Valdir de Oliveira (coord.). Grandes Questões Atuais do Direito Tributário, vol. 19. São Paulo: Dialética, 2015.

BARRETO, Simone Rodrigues Costa. Mutação do Conceito Constitucional de Mercadoria. Tese de Doutorado São Paulo: PUC, 2014.

BARROSO, Luís Roberto. Direito Constitucional Contemporâneo, $2^{a}$ ed. São Paulo: Saraiva, 2010.

BARBOSA, Marcus Vinicius Cardoso. "Direito Tributário e o Supremo Tribunal Federal: passado, presente e futuro" in Universitas JUS, vol. 27, n. 1. Brasília: UNICEUB, 2016. Disponível em www.publicacoesacademicas.uniceub.br Acesso em 05.10.2016. 
Mudança na Jurisprudência do Supremo Tribunal Federal em

Matéria Tributária: segurança jurídica e modulação dos efeitos temporais das decisões judiciais. Parecer disponível em http://www.luisrobertobarroso.com.br/ Acesso em 07.11.2016

BECKER, Alfredo Augusto. Teoria Geral do Direito Tributário, $3^{a}$ ed. São Paulo: Lejus, 1998.

BEISSE, Heinrich. "O Critério Econômico na Interpretação das Leis Tributárias Segundo a mais Recente Jurisprudência Alemã." In: MACHADO, Brandão (coord.) Direito Tributário: estudos em homenagem ao Prof. Ruy Barbosa Nogueira. São Paulo: Saraiva, 1984.

BOITEUX, Fernando Netto. "Incidência da Cofins sobre as variações cambiais". In Revista Dialética de Direito Tributário. São Paulo: Dialética, fevereiro/2004, no 101.

BOSELLO, Furio. "A Formulação da Norma Tributária e as Categorias Jurídicas Civilísticas." In: MACHADO, Brandão (coord.) Direito Tributário: estudos em homenagem ao Prof. Ruy Barbosa Nogueira. São Paulo: Saraiva, 1984.

BRITTO, Lucas Galvão de. "Dividir, Definir e Classificar: conhecer é recortar o mundo.” In CARVALHO, Paulo de barros (coord.). CARVALHO, Autora Tomazini de (org). Constructivismo Lógico-Semântico. São Paulo: Noeses, 2014, Vol. I.

BULOS, Uadi Lammêgo. Mutação Constitucional. São Paulo: Saraiva, 1997.

CARRAZZA, Roque Antônio. Curso de Direito Constitucional Tributário, $23^{\mathrm{a}}$ ed. São Paulo: Malheiros, 2006.

" "Contribuições de intervenção no domínio econômico - Perfil Constitucional - Inexigibilidade de Contribuição para o INCRA - Questões conexas." in Revista Dialética de Direito Tributário. São Paulo: Dialética, no 171, dez/2009.

ICMS, $17^{\mathrm{a}}$ ed. São Paulo: Malheiros, 2015

CARVALHO, Paulo de Barros. Direito Tributário, Linguagem e Método, $3^{\mathrm{a}}$ ed. São Paulo: Noeses, 2009.

Curso de Direito Tributário, 23ª ed. São Paulo: Saraiva, 2011.

COÊLHO, Sacha Calmon Navarro. Comentários à Constituição de 1988: sistema tributário. Rio de Janeiro: Forense, 2005.

Forense, 2009. Curso de Direito Tributário Brasileiro, $10^{\mathrm{a}}$ ed. Rio de Janeiro:

Teoria Geral do Tributo, da Interpretação e da Exoneração Tributária (o significado do parágrafo único do art. 116 do CTN), $3^{\mathrm{a}}$ ed. São Paulo: Dialética, 2003. 
COSTA, Regina Helena. Princípio da Capacidade Contributiva, $4^{\mathrm{a}}$ ed. São Paulo: Malheiros, 2012.

DERZI, Misabel de Abreu Machado. Direito Tributário, Direito Penal e Tipo, $2^{\mathrm{a}}$ ed. São Paulo: Revista dos Tribunais, 2007.

Notas de atualização em BALEEIRO, Aliomar. Direito Tributário Brasileiro, 12 $2^{\mathrm{a}}$ ed. Rio de Janeiro: Forense, 2013.

Modificações da Jurisprudência no Direito Tributário: Proteção da Confiança, boa-fé objetiva e irretroatividade como limitações constitucionais do poder judicial de tributar. São Paulo: Noeses, 2009.

Notas de atualização em BALEEIRO, Aliomar. Limitações

Constitucionais ao Poder de Tributar, $8^{\mathrm{a}}$ ed. Rio de Janeiro: Forense, 2010.

" "O planejamento tributário e o buraco do Real. Contraste entre a Completabilidade do Direito Civil e a Vedação da Completude no Direito Tributário." In: FERREIRA, Eduardo Paz et. al. (coord.). Estudos em Homenagem ao Professor Doutor Alberto Xavier. Coimbra: Almedina, 2013, Vol. II.

DÓRIA, Antonio Roberto Sampaio. Discriminação de Rendas Tributárias. São Paulo: José Bushatsky Editor, 1972.

Elisão e Evasão Fiscal. São Paulo: José Bushatsky Editor, 1977.

DORNELLES, Francisco. "O Sistema Tributário da Constituição de 1988" In Estudos Legislativos do Senado Federal, Vol. IV: Constituição de 1988: O Brasil 20 anos depois. Estado e Economia em Vinte Anos de Mudanças. Disponível em http://www12.senado.gov.br Acesso em 03.07.2014.

FALCÃO, Amílcar Araújo. Fato Gerador da Obrigação Tributária, $1^{\mathrm{a}}$ ed. Rio de Janeiro: Edições Financeiras, 1964.

FERRAZ, Anna Candida da Cunha. Processos Informais de Mudança da Constituição: mutações constitucionais e mutações inconstitucionais. São Paulo: Max Limonad, 1986.

FONSECA, Fernando Daniel de Moura. Normas Tributárias e a Convergências das Regras Contábeis Internacionais. Rio de Janeiro: Lumen Juris, 2014.

LIMA, Daniel Serra. "A Relação entre os Conceitos Jurídico e

Contábil de Ágio Antes e Depois da Reforma da Lei das S/A: o problema da interdisciplinaridade no direito tributário" in MANEIRA, Eduardo; SANTIAGO, Igor Mauler. (coord.). O Ágio no Direito Tributário e Societário: questões atuais. São Paulo: Quartier Latin, 2015.

GAMA, Tácio Lacerda. Competência Tributária: fundamentos para uma teoria da nulidade, $2^{\mathrm{a}}$ ed. São Paulo: Noeses, 2011. 
GENY, Fr. "O particularismo no direito fiscal" in Revista de Direito Administrativo. Rio de Janeiro, v. 20, jan/1950. p. 6-31. Disponível em: http://bibliotecadigital.fgv.br/ Acesso em: 24.11.2016.

GODOI, Marciano Seabra de; SALIBA, Luciana Goulart Ferreira. "Interpretação e Aplicação da Lei Tributária" in MACHADO, Hugo de Brito (coord.) Interpretação e Aplicação da Lei Tributária. São Paulo: Dialética, 2010.

"Tributo e Solidariedade Social." in GRECO, Marco Aurélio; GODOI, Marciano Seabra de. (coord.). Solidariedade Social e Tributação. São Paulo: Dialética, 2005.

GRAU, Eros Roberto. "A Interpretação do Direito e a Interpretação do Direito Tributário" in CARVALHO, Maria Augusta Machado de (coord.). Estudos de Direito Tributário em Homenagem à Memória de Gilberto de Ulhôa Canto. Rio de Janeiro: Forense, 1998.

2014

Porque Tenho Medo dos Juízes, $6^{\text {a }}$ ed. São Paulo: Malheiros,

GRECO, Marco Aurélio. Planejamento Tributário, $3^{\text {a }}$ ed. São Paulo: Dialética, 2011.

"Três Papeis da Legalidade Tributária." In: RIBEIRO, Ricardo Lodi; ROCHA, Sérgio André (Coord.). Legalidade e Tipicidade no Direito Tributário. São Paulo: Quartier Latin, 2008.

"Solidariedade Social e Tributação" in GRECO, Marco Aurélio; GODOI, Marciano Seabra de. (coord.). Solidariedade Social e Tributação. São Paulo: Dialética, 2005.

GUASTINI, Riccardo. Interpretar y Argumentar. MEDINA, Silvina Álvarez (trad.). Madrid: Centro de Estudios Politicos y Constitucionales, 2014.

Latin, 2005.

Das fontes às Normas. BINI, Edson (trad.). São Paulo: Quartier

Distinguiendo: estúdios de Teoria e Metateoria del Derecho.

BELTRÁN, Jordi Ferrer i (trad). Barcelona: Gedisa, 1999.

Teoría e Ideologia de la Interpretación Constitucional.

CARBONELL, Miguel et. al. (trad.). Madrid: Minima Trotta, 2010.

GUIBOURG, Ricardo A. GHIGLIANI, Alejandro M. GUARINONI, Ricardo V. Introducción al Conocimiento Científico. Buenos Aires: EUDEBA, 1985.

HÄBERLE, Peter. Hermenêutica Constitucional: a sociedade aberta dos intérpretes da Constituição: contribuição para interpretação pluralista e 'procedimental da Constituição. MENDES, Gilmar Ferreira (trad.). Porto Alegre: Sérgio Antônio Fabris Editor, 1997. 
HART. Herbert Lionel Adolphus. O Conceito de Direito. SETTE-CÂMARA, Antonio de Oliveira (trad.). São Paulo: WMF Martins Fontes, 2009.

HESSE, Konrad. A Força Normativa da Constituição. MENDES, Gilmar Ferreira (trad.). Porto Alegre: Sérgio Antônio Fabris Editor, 1991.

"Limites de la mutación constitucional". In: VILLALÓN, Pedro Cruz (Org.). Escritos de Derecho Constitucional, $2^{\mathrm{a}}$ ed. VILLALÓN, Pedro Cruz (trad.). Madrid [ES]: Centro de Estúdios constitucionales, 1992.

HORVATH, Estevão. "Conflitos de Competência (IPI, ICMS, ISS, etc.)"in DERZI, Misabel Abreu Machado (org.). Competência Tributária. Belo Horizonte: Del Rey, 2011.

Paulo: Dialética, 2009.

Contribuições de Intervenção no Domínio Econômico. São

O Princípio do Não-Confisco no Direito Tributário. São Paulo:

Dialética, 2002.

ICHIHARA, Yoshiaki. "Interpretação e Aplicação da Lei Tributária" in MACHADO, Hugo de Brito (coord.) Interpretação e Aplicação da Lei Tributária. São Paulo: Dialética, 2010.

JALORETTO, Cláudio. Seis Décadas de Déficit Público no Brasil. Monografia premiada com menção honrosa no XIV Prêmio Tesouro Nacional. Brasília: ESAF, 2009. Disponível em https://www.tesouro.fazenda.gov.br

JELLINEK, Georg. Reforma y Mutación de la Constitución. FÖRSTER, Christian (trad.). Madrid [ES]: Centro de Estudios Constitucionales, 1991.

KAUFMANN, Arthur. Filosofia do Direito, $5^{\mathrm{a}}$ ed. CORTÊS, Antonio Ulisses (trad.). Lisboa (PT): Fundação Calouste Gulbenkian, 2014.

KELSEN, Hans. Teoria Pura do Direito, $8^{\text {a }}$ ed. MACHADO, João Baptista (trad.) São Paulo: WMFMartins, 2009.

LARENZ, Karl. Metodologia da Ciência do Direito, $3^{\text {a }}$ ed. LAMEGO, José (trad.). Lisboa-PT: Fundação Calouste Gulbekian, 1997.

LESSA, Donovan Mazza. LIMA, Daniel Serra. "A declaração de inconstitucionalidade de benefícios fiscais de ICMS e a impossibilidade de exigir retroativamente o imposto do contribuinte de direito" in PASIN, João Bosco Coelho et al (coord.) Revista de Direito Tributário e Finanças Públicas, $\mathrm{n}^{\mathrm{o}}$ 30. Porto Alegre: Magister, janeiro/fevereiro de 2012, p. 5-19.

LEWANDOWSKI, Enrique Ricardo. Pressupostos materiais e formais da intervenção federal no Brasil. São Paulo: Revista dos Tribunais, 1994. 
MACHADO, Hugo de Brito (org.). A Imunidade do Livro Eletrônico. São Paulo: Atlas, 2003.

Curso de Direito Tributário, 29ª ed. São Paulo: Malheiros, 2008.

MACHADO, Raquel Cavalcanti Ramos. Competência Tributária: entre a rigidez do sistema e a atualização interpretativa. São Paulo: Malheiros, 2014.

MACHADO, Schubert de Farias. "Interpretação e Aplicação da Lei Tributária" in MACHADO, Hugo de Brito (coord.) Interpretação e Aplicação da Lei Tributária. São Paulo: Dialética, 2010.

MALERBI, Diva Prestes Marcondes. Elisão tributária. São Paulo: Revista dos Tribunais, 1984.

MANEIRA, Eduardo. "Princípio da Legalidade: Especificação Conceitual $\mathrm{x}$ Tipicidade”. In Revista Internacional de Direito Tributário. Belo Horizonte: vol. 1, n. 1 , p. $47 / 58$, jan-jun/2004.

. "Sistema Tributário Nacional e Princípio da Legalidade" in COÊLHO, Sacha Calmon Navarro (coord.) Segurança Jurídica: irretroatividade das decisões judiciais prejudiciais aos contribuintes. Forense: Rio de Janeiro, 2013.

MARTINS, Natanael. “A nova contabilidade pós Medida Provisória n 627/2013: normas contábeis e normas de tributação - dois corpos distintos de linguagem e de aplicação." In. MOSQUERA, Roberto Quiroga; LOPES, Alexsandro Broedel (Coord.). Controvérsias jurídico-contábeis (aproximações e distanciamentos). $5^{\circ}$ Vol. São Paulo: Dialética, 2014.

MAXIMIlianO, Carlos. Hermenêutica e Aplicação do Direito, $18^{a}$ ed. Rio de Janeiro: Forense, 1999.

MACCORMICK, Neil. Argumentação Jurídica e Teoria do Direito. BARCELLOS, Waldéa (trad.) São Paulo: Martins Fontes, 2006.

MENDES, Gilmar Ferreira et al. Curso de Direito Constitucional, $5^{\text {a }}$ ed. São Paulo: Saraiva, 2010.

MENDONÇA, Cristiane. Competência Tributária. São Paulo: Quartier Latin, 2004.

MELO, Marcia Soares. "Interpretação e Aplicação da Lei Tributária" in MACHADO, Hugo de Brito (coord.) Interpretação e Aplicação da Lei Tributária. São Paulo: Dialética, 2010.

MOREIRA, Eduardo Ribeiro. Teoria da Reforma Constitucional. São Paulo: Saraiva, 2012.

MÜLLER, Friedrich. Métodos de Trabalho de Direito Constitucional, $3^{\text {a }}$ ed. NAUMANN, Peter (trad.) Rio de Janeiro: Renovar, 2005. 
MURPHY, Liam; NAGEL, Thomas. O Mito da Propriedade: os impostos e a justiça. CIPOLLA, Marcelo Brandão (trad.) São Paulo: Martins Fontes, 2005.

NABAIS, José Casalta. O Dever Fundamental de Pagar Impostos: contributo para a compreensão constitucional do estado fiscal contemporâneo. Coimbra-PT: Almedina, 2009.

NEVES, Marcelo. "Pesquisa Interdisciplinar no Brasil: o paradoxo da interdisciplinaridade" in Revista do Instituto de Hermenêutica Jurídica vol. 1, no 3. Porto Alegre: Instituto de Hermenêutica Jurídica, 2005.

NOGUEIRA, Johnson Barbosa. A Interpretação Econômica no Direito Tributário. São Paulo: Resenha Tributária, 1982.

NOGUEIRA, Ruy Barbosa. Curso de Direito Tributário, 9a ed. São Paulo: Saraiva, 1989.

OLIVEIRA, Ricardo Mariz. Fundamentos do Imposto sobre a Renda. São Paulo: Quartier Latin, 2008.

PATTERSON, Dennis. "Interpretation in Law". San Diego Law Review, vol. 42. San Diego (US), Ashgate, 2005.

PISCITELLI. Tathiane dos Santos. Argumentando pelas Consequências no Direito Tributário. São Paulo: Noeses, 2011.

PIZZOLIO, Reinaldo. Competência Tributária e Conceitos Constitucionais. São Paulo: Quartier Latin, 2006.

POLIZELLI, Victor Borges. Princípio da Realização da Renda. São Paulo: Quartier Latin, 2012.

RAMOS, Carlos Henrique. Mutação Constitucional: constituição e identidade constitucional evolutiva. Curitiba: Juruá, 2013.

RIBEIRO, Ricardo Lodi. A Segurança Jurídica do Contribuinte: Legalidade, não surpresa e proteção à confiança legítima. Rio de Janeiro: Lumen Juris, 2008.

Lumen Juris, 2003.

Justiça, Interpretação e Elisão Tributária. Rio de Janeiro:

“A Tipicidade Tributária.” In: RIBEIRO, Ricardo Lodi; ROCHA, Sérgio André (Coord.). Legalidade e Tipicidade no Direito Tributário. São Paulo: Quartier Latin, 2008.

ROCHA, Sergio André. "A Deslegalização no Direito Tributário Brasileiro Contemporâneo: Segurança Jurídica, Legalidade, Conceitos Indeterminados, Tipicidade e Liberdade de Conformação da Administração Pública." In: RIBEIRO, Ricardo Lodi; ROCHA, Sérgio André (Coord.). Legalidade e Tipicidade no Direito Tributário. São Paulo: Quartier Latin, 2008. 
. "O que é Formalismo Tributário?". Revista Dialética de Direito

Tributário, $\mathrm{n}^{\circ}$ 227. São Paulo: Dialética, agosto/2014, p 146-155.

RODRIGUEZ Caio F. Grandchamp, Marcio S. "Teorias contemporâneas da interpretação constitucional: entrevista com o ministro Antonin Scalia", da Suprema Corte dos EUA in Revista de Direito Administrativo, vol. 250. ARGUELHES, Diego Werneck (trad.) São Paulo: Fundação Getúlio Vargas, 2009, p. 23-25. Disponível em http://bibliotecadigital.fgv.br/ Acesso em 19.09.2016.

SILVA, José Afonso da. "Mutaciones Constitucionales." Cuestiones Constitucionales Revista Mexicana de Derecho Constitucional, vol. 01, jan/1999. Disponível em https://revistas.juridicas.unam.mx Acesso em 04.11.2016

SCALIA, Antonin et al. A Matter of Interpretacion: federal courts and the law. Princeton [US]: Princeton University Press, 1997.

SCHAUER, Frederick. Playing by the Rules: a phylosophical examination of rulebased decision-making in law and in life. Oxford: Clarendon, 2002.

. “Formalism”. Yale Law Journal. Vol. 97. n 4, 1988, p. 510-585.

SCHOUERI, Luis Eduardo. "Discriminação de Competências e Competência Residual" In SCHOUERI, Luis Eduardo; ZILVETI, Fernando Aurélio (coord.) Direito Tributário: estudos em homenagem à Brandão Machado. São Paulo: Dialética, 1998.

Direito Tributário. São Paulo: Saraiva, 2011.

Forense, 2005.

Normas Indutoras e Intervenção Econômica. Rio de Janeiro:

SOUSA, Rubens Gomes de. Compêndio de Legislação Tributária. Edição Póstuma. São Paulo: Resenha Tributária, 1975.

STRECK, Lênio Luiz et. al. "Ulisses e o canto das sereias: sobre ativismos judiciais e os perigos da instauração de um "terceiro turno da constituinte"" in Revista de Estudos Constitucionais, Hermenêutica e Teoria do Direito (RECHTD), vol. I. São Leopoldo: Unisinos, julho/dez 2009. Disponível em http://revistas.unisinos.br/ Acesso em 07.11.2016

STRUCHINER, Noel. "Indeterminação e Objetividade: quando o direito diz o que não queremos ouvir" in MACEDO JR., Ronaldo Porto. BARBIERI, Catarina Helena Cortada. Direito e Interpretação: racionalidades e instituições. São Paulo: Saraiva, 2011.

SUNSTEIN, Cass R. "Deve o Formalismo ser Defendido Empiricamente?" in A Justificação do Formalismo Jurídico: textos em debate. RODRIGUEZ, José Rodrigo (org.). São Paulo: Saraiva, 2011. 
SUPREMO TRIBUNAL FEDERAL. Assessoria de Gestão Estratégica. Números da Repercussão Geral. Disponível em http://www.stf.jus.br Acesso em 05.10.2016.

TIPKE, Klaus. LANG, Joachim. Direito Tributário, $18^{\mathrm{a}}$ ed. Tradução de FURQUIM, Luiz Dória. Porto Alegre: Sérgio Antonio Fabris, 2008, Vol I.

;) YAMASHITA, Douglas. Justiça Fiscal e Princípio da

Capacidade Contributiva. São Paulo: Malheiros, 2002.

TORRES, Heleno Taveira. Direito Constitucional Financeiro: teoria da constituição financeira. São Paulo: RT, 2014.

Direito Constitucional Tributário e Segurança Jurídica: metódica da segurança jurídica do sistema constitucional tributário, $2^{\mathrm{a}}$ ed. São Paulo: Revista dos Tribunais, 2012.

. Direito Tributário e Direito Privado. Autonomia privada, simulação e elusão tributária. São Paulo: Editora Revista dos Tribunais, 2003.

TORRES, Ricardo Lobo. "Existe um Princípio Estrutural da Solidariedade?" in GRECO, Marco Aurélio; GODOI, Marciano Seabra de. (coord.). Solidariedade Social e Tributação. São Paulo: Dialética, 2005.

"Interpretação e Integração da Lei Tributária" in MACHADO, Hugo de Brito (coord.) Interpretação e Aplicação da Lei Tributária. São Paulo: Dialética, 2010.

. "Legalidade Tributária e Riscos Sociais." In Revista Dialética de Direito Tributário. São Paulo: Dialética, n. 59, ago/2000.

Normas de Interpretação e Integração do Direito Tributário, $3^{\text {a }}$ ed. Rio de Janeiro: Renovar, 2006.

. "O princípio da Tipicidade no Direito Tributário.” In: RIBEIRO, Ricardo Lodi; ROCHA, Sérgio André (Coord.). Legalidade e Tipicidade no Direito Tributário. São Paulo: Quartier Latin, 2008.

Tratado de Direito Constitucional, Financeiro e Tributário: valores e princípios constitucionais tributários. Rio de Janeiro: Renovar, vol. II, 2014.

Sistemas Constitucionais Tributários. Rio de Janeiro: Forense, 1986.

TRIBE, Laurence H. DORF, Michael C. On Reading the Constitucion. London [EN]: Harvard University Press, 1991.

TROTABAS, Louis. "Ensaio sôbre o Direito Fiscal" in Revista de Direito Administrativo, Rio de Janeiro, v. 26, p. 34-59, jan/1951. Disponível em: http://bibliotecadigital.fgv.br/ Acesso em: 24.11.2016. 
VANONI, Ezio. Natureza e Interpretação das Leis Tributárias. SOUSA, Rubens Gomes de (trad.). Rio de Janeiro: Edições Financeiras, 1932.

VELlOSO, Andrei Pitten. Conceitos e Competências Tributárias. São Paulo: Dialética, 2005.

Livraria do Advogado, 2016.

Constituição Tributária Interpretada, $3^{\mathrm{a}}$ ed. Porto Alegre:

XAVIER, Alberto. O Principio da Legalidade e da Tipicidade da Tributação. São Paulo: RT, 1977.

Forense, 1982,

Direito Tributário e Empresarial: pareceres. Rio de Janeiro: Paulo: Dialética, 2001.

ZILVETI, Fernando Aurélio. Obrigação Tributária: fato gerador e tipo. São Paulo: Quartier Latin, 2009.

"Tipos e Linguagem: a gênese da igualdade na tributação." In: RIBEIRO, Ricardo Lodi; ROCHA, Sérgio André (Coord.). Legalidade e Tipicidade no Direito Tributário. São Paulo: Quartier Latin, 2008. 